VIDA UNIVERSITARIA

\title{
COSMOVISIONES Y PRÁCTICAS ANCESTRALES DE LOS PASTOS PARA CONSTRUIR LA PAZ REGIONAL
}

\author{
COSMOVISIONS AND ANCESTRAL PRACTICES OF THE PASTOS TO \\ BUILD REGIONAL PEACE
}

\section{COSMOVISÕES E PRÁTICAS ANCESTRAIS DOS PASTOS PARA CONSTRUIR A PAZ REGIONAL}

\author{
MESA MANOSALVA_Edgar Guillermo
}

Candidato a Doctor, Facultad de Ciencias de la Educación, Universidad de Granada, España. Docente en Facultad de Ciencias de la Educación, Universidad de Nariño. Email: manosalva50@gmail.com, Colombia

Recibido: 30 de mayo de 2017 Aprobación definitiva: 23 de junio de 2018

DOI: http://dx.doi.org/10.22267/rtend.181901.95

\section{RESUMEN}

Este artículo ${ }^{1}$ está orientado al análisis interpretativo de las cosmovisiones y prácticas ancestrales de los Pastos en torno a la pachamama, minga, religiosidad, cuento pastuso y carnaval de negros y blancos, con el objetivo de redimensionar sus aportes epistemológicos y pedagógicos en la construcción de la paz regional. En el marco del paradigma de investigación cualitativa y del enfoque etnográfico se emplearon las técnicas de observación participante, la entrevista en profundidad, las conversaciones informales y la revisión documental para la recolección de información. Se entrevistaron a seis docentes de la Universidad de Nariño, se observaron las prácticas socioculturales en cinco municipios de la región andina nariñense y se revisaron documentos, revistas y libros. Los resultados obtenidos

1 Proyecto de Tesis Doctoral, "Aportes étnico-culturales y educativos de docentes de la Universidad de Nariño para construir la paz en el postconflicto", en la Facultad de Ciencias de la Educación, Universidad de Granada, España. 
son valiosos y pertinentes para: visibilizar el colectivismo productivo y económico; valorar la minga o manos prestadas base del tejido social; entender que la religiosidad popular guarda respeto sagrado a la naturaleza, al absoluto y al prójimo; comprender que el humor es risa, alegría, esparcimiento y felicidad; y que el carnaval es una fiesta mestiza, pluriétnica e intercultural.

Palabras clave: cosmovisiones, diversidad, los Pastos, paz, prácticas ancestrales.

JEL: A13, Q20, R50

\section{ABSTRACT}

This article is oriented to the interpretative analysis of the cosmovisions and ancestral practices of the "Pastos" around the pachamama, minga, religiosity, regional tales and the black and white carnivals, with the aim of resizing their epistemological and pedagogical contributions in the construction of regional peace. Within the framework of the qualitative research paradigm and the ethnographic approach, participant observation techniques, in-depth interviews, informal conversations and documentary review for the collections of information were used. Six teachers from the University of Nariño were interviewed, sociocultural practices were observed in five municipalities, magazines and books were reviewed. The results obtained are valuable and relevant to: make visible the productive and economic collectivism; assess the minga or borrowed hands based on the social fabric; understand that popular religiosity holds sacred respect to nature, to the absolute and to the neighbor; understand that humor in laughter, joy, recreation and happiness; and that the carnival is a mestizo, multi-ethnic and intercultural party.

Keywords: cosmovisions, diversity, the Pastos, peace, ancestral practices.

JEL: A13, Q20, R50 


\section{RESUMO}

Este artigo é orientado para a análise interpretativa das visões de mundo e práticas ancestrais de os Pastos em torno do pachamama, minga, religiosidade, conto pastuso, e carnaval negros y brancos, com o objetivo de redimensionar suas contribuções epistemológicas e pedagógicas na construção da paz regional. No ãmbito do paradigma de pesquisa qualitativa e da abordagem etnográfica, foram utilizadas técnicas de observação participante, entrevistas em profundidade, conversas infromais e revisão documental para a coleta de informações. Seis professores da Universidade de Nariño foram entrevistados, práticas socioculturais foram observadas em cinco municipios da região andina de Nariño, e documentos, revistas e livros foram revisados. Os resultados obtidos são valiosos e relevantes para: tornar visível o coletivismo produtivo e econômico; avaliar a minga ou mãos emprestadas com base no tecido social; entender que a religiosidade popular tem um respeito sagrado pela natureza, pelo absoluto e pelo próximo; entender que humor é riso, alegria, recreação e felicidade; e que o carnaval é uma festa mestiça, multiétnica e intercultural.

Palavras-chave: visões de mundo, diversidade, Pastos, paz, práticas ancestrais.

JEL: A13, Q20, R50.

\section{INTRODUCCIÓN}

EnelsuroccidentedeColombia, departamentode Nariño, especialmente en la región andina, las cosmovisiones y prácticas ancestrales orientan el quehacer cotidiano, celebrativo y festivo de las comunidades indígenas y mestizas del sector rural y urbano; regulan las actividades agrícolas, ganaderas y productivas; inciden en las conductas personales, familiares y sociales; y contienen referentes epistemológicos para el pensamiento andino y la paz. En este marco se abordan algunas concepciones de las que se nutre el sistema de valores sociales, económicos, religiosos, políticos y culturales de los Pastos.

Así, por ejemplo, "la pacha" es el concepto del tiempo/espacio y "mama" hace alusión a la tierra; entonces, pachamama es la concepción 
del tiempo/espacio asociada, específicamente, a la madre naturaleza. La minga o manos prestadas es un accionar prehispánico colectivo de servicio, de solidaridad, de experiencias de vida, del tejido social, del buen vivir y de la pervivencia. La religiosidad es el conjunto de prácticas sagradas y profanas expresadas con sencillez, espontaneidad y naturalidad en ciertas épocas del año. El cuento pastuso, es un dicho, una ocurrencia o historia breve graciosa, narrada o dibujada cuya función es el entretenimiento, la risa, la alegría, el ocio y la felicidad. Finalmente, el carnaval de negros y blancos es el escenario de la cultura ancestral, popular, citadina, urbana, campesina, indígena, afrocolombiana y mestiza, espacio para compartir sus mejores riquezas.

Este artículo explora estos sentidos; por ello, se estructura en una descripción breve de la historia de los Pastos, el análisis de las cosmovisiones y prácticas ancestrales, diversidad, pensamiento andino y construcción de paz.

\section{METODOLOGÍA}

La metodología de investigación se centró en el paradigma cualitativo y etnográfico empleando la observación del participante, la entrevista en profundidad, las conversaciones informales y la revisión documental como técnicas de recolección de información. Se entrevistaron seis docentes de la Universidad de Nariño, y se observaron las prácticas socioeconómicas de campesinos e indígenas en cinco municipios: Pupiales (veredas Imbula Chico y Miraflores), Puerres, Gualmatán, Ipiales, Túquerres y Pasto, como también en las localidades de Cujacal alto, Campanero y San Antonio de Casanare pertenecientes a Pasto. La descripción analítica permitió la exposición de datos empíricos para mostrar y hacer entendible el fenómeno étnico-cultural y educativo, a fin de construir cuatro categorías con sus respectivas subcategorías para clasificar, sistematizar, contrastar y estructurar la información en matrices codificadas de acuerdo con las veinte preguntas de las entrevistas y observaciones técnicamente elaboradas, para luego proseguir con la elaboración de los capítulos de la tesis doctoral. Parte de los resultados obtenidos se presentan en este artículo, en especial, lo que corresponde a la categoría cosmovisiones y prácticas ancestrales y su relación con la categoría hermenéutica de la paz. 


\section{COSMOVISIONES Y PRÁCTICAS ANCESTRALES.}

Los Pastos llegaron desde el sur hacia la zona central de los Andes y "se localizaron en el espacio geográfico comprendido entre el río Chota (Ecuador) al sur, hasta el actual municipio de Ancuya (Colombia) y el río Curiaco localizado entre los municipios de Tangua y Funes; principalmente en el nudo de los Pastos" (Afanador, 2011:12), actualmente están ubicados en el sur de Colombia y el norte de Ecuador.

A finales del siglo XV, los Pastos estuvieron influenciados por los Incas al mando de Huayna-Cápac, quien con su ejército instaló colonias al lado y lado del Rumichaca y trajo yanaconas del Ecuador para enseñar el quichua y la cultura incaica. Posteriormente, los españoles dominaron la región, fundaron la ciudad de San Juan de Pasto en 1539 y gobernaron hasta la independencia en 1824; sin embargo, y a pesar de su poderosa influencia, la cultura incaica se había introyectado en lo más profundo de la conciencia del pueblo. Al respecto, Huanacuni (2010:15) afirma:

En gran parte de los pueblos de la región andina de Colombia, Ecuador, Bolivia, Perú, Chile y Argentina (...) pervive la cosmovisión ancestral o visión cósmica, que es una forma de comprender el mundo y expresarse en las relaciones de vida (...) con una esencia común: el paradigma comunitario basado en la vida en armonía y el equilibrio con el entorno.

El ser humano en su relación con la naturaleza construye conocimientos y adquiere experiencias que las transmite socialmente formando tramas complejas, que en el transcurrir de la historia connotan sistemas socioculturales con particularidades especiales y con estructuras semióticas y lingüísticas de profundas significaciones. El concepto de cultura es esencialmente un concepto semiótico por los significados y sentidos que se le dan a las cosas, situaciones y comportamientos. Es un conjunto de textos y contextos dentro de los cuales tienen significado los acontecimientos sociales, los modos de conducta, las instituciones y los procesos sociales.

Cada comunidad, pueblo y sociedad ha construido su propia cultura, su sistema de relaciones, su gobernanza, su educación, su territorio, su justicia y en ese marco transita su devenir. Geertz (2003:108) afirma que: 
Las sociedades contienen en sí mismas sus propias interpretaciones. Lo único que se necesita es aprender la manera de tener acceso a ellas, puesto que los seres humanos viven envueltos en tramas de significación, que deben interpretarse para entender sus actos.

Por ello, la función de la cultura es dotar de sentido al mundo y hacerlo comprensible; en este sentido, las cosmovisiones son la manera de ver e interpretar el mundo. Muñoz y Molina (1998:36) afirman que la cosmovisión es "Un conjunto de ideas que articulan y ordenan los valores y las ideas de una sociedad, e indirectamente, hacia las cuales se proyectan las prácticas, de acuerdo con esquemas culturales-religiosos, filosóficos, estéticos, científicos y lingüísticos", son procedimientos que, en definitiva, suministran patrones o modelos para organizar los procesos actitudinales y conductuales sociales y personales.

Por su parte Geertz (2003:108) afirma que "es un sistema de concepciones expresadas en formas simbólicas por medio de las cuales la gente se comunica, perpetúa y desarrolla su conocimiento sobre las actitudes hacia la vida". De lo anterior se infiere que éstas orientan el quehacer de las comunidades indígenas, campesinas y mestizas del sector rural y urbano; regulan las actividades y las acciones agrícolas, ganaderas y productivas; y tienen incidencia en las conductas sociales y familiares.

\subsection{La cosmovisión pachamama.}

En el caso de los Pastos, la pachamama es fuente de prácticas agrícolas, laborales, económicas y base de la concepción del bien común. Para Bajtín (1987:11), "la sucesión de las estaciones, la siembra, la concepción, la muerte y el crecimiento son los componentes de esta vida productora". La noción implícita del tiempo contenida en esas antiquísimas imágenes es la noción del tiempo cíclico de la vida natural y biológica.

En este sentido, la concepción más difundida de la pachamama es la que considera a la tierra como una madre protectora y proveedora porque cobija a los seres humanos, posibilita la vida y favorece la fecundidad y la fertilidad. El pueblo de los Pastos ha logrado desarrollar una concepción 
de las relaciones del ser humano con la naturaleza, en tanto que es expresión misma de la naturaleza, es pariente de los pájaros, pariente del viento, pariente de las aguas, por ser hijos todos de la pachamama. Mamián (2004:64) dice que para los Pastos:

La tierra es la madre: de ella deviene el sustento material y espiritual de los hombres; de su interior se nace y a él se vuelve; es la vida antes y después de la vida. Es el pasado, es el futuro y es el presente; en ella se está como en un regazo.

El concepto de pacha significa tierra, mundo, naturaleza, universo, tiempo; mientras que mama es madre, de su unión resulta madre tierra. La cosmovisión de la pachamama reviste connotaciones religiosas y materiales. Es religiosa por cuanto se considera a la pachamama una diosa que prodiga bienes y servicios. En respuesta a esto hay una adhesión, una ligazón entre el ser humano y esa divinidad de lo cual resulta la religión, que significa atar, vincular fuertemente y forma parte de una religiosidad, es decir, los seres humanos se atan a esa entidad natural. De este modo otros identifican a la pachamama con simbologías marianas cristianas, es decir, con la Virgen de las Lajas, la Virgen del Rosario o la Inmaculada y en los pies una culebra que simboliza la vida y la muerte, una relación entre la armonía y la desarmonía, entre la paz y la guerra, entre el cielo y el infierno.

De la cosmovisión materialista de la pachamama se desprenden infinidad de relaciones referidas a la vida económica y laboral, el cuidado y protección de los recursos, la siembra y cosecha, el trabajo y la ética, bien común y sociedad entre otros, es decir, se produce un conocimiento social sobre la agricultura, las semillas, los abonos, los productos, los descansos, las estaciones, la relación con los ciclos lunares, con el solsticio, con las lluvias, con los seres vivientes y, muy especialmente, la relación de los seres humanos con la naturaleza.

De esta visión materialista se vislumbran enseñanzas, entre ellas, económicas porque en la relación del ser humano con la naturaleza se encuentran las riquezas, los bienes y los frutos que alimentan y sustentan la vida; laborales porque a través del trabajo se consiguen los alimentos, se producen saberes, conocimientos y tecnologías, se desarrollan 
capacidades, habilidades y destrezas para la realización personal y social; productiva porque la tierra provee los recursos y materiales que los seres humanos necesitan para su bienestar. En este sentido, el bien común es lo que beneficia a todos, está destinado al bienestar social, contribuye a la felicidad y a la perfección del ser humano.

Al mantener una actitud de respeto con la madre tierra se posibilitan relaciones de reciprocidad y complementariedad porque se toma lo necesario para vivir, se protegen los suelos, se cuidan las aguas, las aves, los insectos, se abona y fertiliza con elementos de la misma naturaleza, se siembran nuevos árboles, se dan intervalos entre las siembras, se cultivan variedad de productos, se conservan las mejores semillas para el trueque e intercambio y se cualifican las técnicas de cultivo y comercialización. Por desgracia, en la relación con la naturaleza, no siempre reina el equilibrio y la armonía, "hemos crecido pensando que éramos sus propietarios y dominadores, autorizados a expoliarla" (Papa Francisco, 2015:1).

\subsection{La cosmovisión minga.}

La minga es una práctica ancestral de los pueblos andinos influenciados por la cultura incaica que significa préstamo de las manos, ayuda mutua, cooperación, servicio y solidaridad. Es la manera informal de trabajo y por el préstamo de las manos se reciben alimentos y especies; este intercambio es importante para mantener una economía básica en la comunidad y es el eje de la cosmovisión andina: dar para recibir.

Hoy en día, este término también se aplica al trabajo intelectual, por ello se habla de minga del pensamiento, minga de las ideas, minga educativa y no solamente se practica entre las comunidades indígenas sino también entre las comunidades mestizas, campesinas y urbanas. La minga en la vida cotidiana de las comunidades es complementariedad y solidaridad; es una práctica social que fortalece las relaciones, estrecha los lazos de amistad, genera espacios de ayuda, tolerancia y posibilita la convivencia, el buen vivir, la solución de problemas y la producción de conocimiento. 
Habría que decir también que la fuerza espiritual de las manos prestadas proyecta el bienestar social, la economía solidaria y la cooperación de las comunidades. En la dinámica de las relaciones comunitarias es interesante la analogía que se puede hacer entre el tejido social y el tradicional telar andino. El telar es utilizado por las abuelas para tejer toda clase de textiles, especialmente cobijas, ruanas, bufandas, cojines, manteles, entre otros elementos para el hogar, pero también como medio de subsistencia. La trama es el conjunto de hilos paralelos en un tejido transversal a la urdimbre. Para hacer el tejido es fundamental la urdimbre, es decir, los hilos colocados en paralelo y a lo largo, para pasar por ellos la trama.

Algo semejante ocurre con la minga, la cual posibilita el tejido social alimentado por los hilos de la estética, la ética, la economía, la política y la religión y que juntas conforman la urdimbre sociocultural por la cual pasan las tramas de la existencia, por esta razón todos los pueblos participan de urdimbres y tramas. Estas tramas socioculturales enriquecen la dinámica relacional y comunicativa, siendo éstas la base para construir ambientes pacíficos, participativos y democráticos.

\subsection{La cosmovisión religiosa.}

La dimensión religiosa está presente en todas las actividades humanas porque la vida, la madre tierra, el universo y el género humano son sagrados y merecen respeto. La religiosidad se manifiesta en las creencias, los ritos, los cultos, los íconos y las celebraciones. De acuerdo con Mamián (2004:105), entre las comunidades de tradición Pasto:

La religión y la religiosidad no se dan como la devoción y el temor individual a un dios o a unos santos, o como la adhesión a dogmas y creencias escriturarios, ni mucho menos a prácticas como ir a misa, confesarse o comulgar, es una vivencia densa y compleja; espacio-tiempo de relación entre los imaginarios simbólicos, las representaciones míticas, rituales y mágicas con las representaciones espaciales y temporales sociopolíticas.

El contexto para expresar lo religioso es la fiesta, prácticamente durante todo el año hay fiestas patronales a santos y "mamitas", es decir, fiesta a alguna advocación de la Virgen, tales como, la virgen de las 
Lajas, del Rosario, de la Inmaculada Concepción; o santos de la Iglesia como San Juan Bosco, San Pedro y San Pablo; o festividades como Corpus Christi, Inti Raymi, entre otros. Los fiesteros con el apoyo de la familia hacen los preparativos durante todo el año, cuidando los cuyes, las gallinas y los ovejos, ahorrando para comprar el maíz y la panela para el champús, para la pólvora y los vestidos.

En el transcurso del tiempo se mezclaron rituales, cultos y ceremonias ancestrales con la doctrina cristiana dando origen a la religiosidad popular, atizada después por sectas protestantes, doctrinas orientales y comunidades religiosas. En este ambiente, las comunidades de esta región andina tienen tiempos cortos y tiempos largos y viven de acuerdo con los ciclos naturales y existenciales, pues, los tiempos cortos se hilan en la cotidianidad de la existencia y los tiempos largos se entretejen con las celebraciones festivas, rituales y culturales, en otras palabras, los ciclos anuales se repiten una y otra vez, tienen la particularidad de la novedad, el encuentro y la celebración colectiva. Estos acontecimientos configuran la espiritualidad de los Pastos, entendida en su sentido amplio: cultivo del espíritu humano, gusto por la trascendencia, pasión por el arte, humanización de lo humano, amor al estudio, a la reflexión y a la práctica de las virtudes.

\subsection{El cuento pastuso.}

Se concibe como un dicho, una ocurrencia o una historia breve, narrada o dibujada que contiene un doble sentido, una burla o una ironía y en cuya estructura se identifican tres elementos distintivos: contenido, origen y objeto. Según Montenegro (2002:215) el contenido "es la burla del atraso de un grupo humano que sufre un notable aislamiento y un evidente rezago económico en el contexto de un país que se moderniza en forma acelerada". En su origen, "son responsables ciertos grupos que acaban de acceder a la modernización y que, con frecuencia, a través de la burla, expresan la inseguridad propia de quienes han adquirido recientemente su condición de personas modernas". Y el más importante, el objeto del chiste: "los pastusos, que sólo pueden explicarse a partir de los rasgos característicos de este grupo humano, así como de su peculiar historia de enfrentamientos y desencuentros con el resto del país". 
Buena parte de la cultura de los Pastos lleva la impronta de la cultura incaica, en el quechua, las fiestas, la gastronomía, el arte, las siembras, etc., y es, precisamente, esto lo que hace que el pastuso sea diferente al resto del país. Montenegro (2002:216) afirma que "los pastusos exhiben rasgos culturales que difieren claramente de los del resto del país", "siempre se sintieron más próximos a Ecuador y al resto de Suramérica" y "probablemente su característica más distintiva sea su manera de hablar, con un lenguaje salpicado incluso de términos quechuas".

En este sentido Sanz (2006:18) afirma que "el quechua es la única lengua de América del Sur que en la época precolombina desempeñó el papel de "lengua de civilización". Propagada por los conquistadores incaicos, se difundió sucesivamente por todo el vasto imperio. Y a finales del siglo XV se había introducido, en el sur de Colombia, lo que es hoy el Departamento de Nariño, y posteriormente los españoles lo utilizaron para sus intereses colonizadores. Así lo expresa Sanz (2006:18), "los conquistadores y colonizadores españoles, para fines de servicio y administración, trajeron desde Quito a muchos centenares de indios (hombres y mujeres) de habla quechua (dialecto quichua), llamados yanaconas (sirvientes)". Un gran número de ellos se quedó en estas tierras y contribuyó a enriquecer el habla local con quechuismos.

Es bien sabido que a comienzos del siglo XIX, en la época de la independencia de Colombia del yugo Español, Pasto asumió la defensa de la corona española y no enarboló la bandera de la libertad, lo que se conoce como realismo pastuso. Zúñiga (2002:66) afirma:

En el distrito de Pasto no se conocieron los Derechos del Hombre y escasamente se tenía noticia de la revolución francesa. El principio democrático según el cual el poder residía en el pueblo apenas se escuchó al iniciarse la gesta emancipadora. La idea provino de Quito y aquí fue considerada un sacrilegio, pues se tenía como verdad inamovible que el poder de los reyes y las autoridades por ellos delegadas, tenía origen divino. Como católicos irreductibles, no dudaban que el poder sólo viene de Dios.

Este revés histórico motivado por el fanatismo religioso, el aislamiento geográfico, el atraso económico, el desconocimiento de los avances humanistas y científicos y el pírrico beneficio económico ofrecido por 
las élites a la servidumbre fueron la causa de malos entendidos. Esta situación dejó huellas en el imaginario social del colombiano sobre la gente de Pasto, y los señalamientos, epítetos, ironías y burlas no cesaron durante mucho tiempo, lo mismo la exclusión y marginalidad, ayudada por las distancias geográficas y las pésimas vías terrestres.

\subsection{Carnaval de Negros y Blancos.}

Declarado Patrimonio Cultural Inmaterial de la Humanidad por la UNESCO en 2009 le otorga un significado profundo a la cultura regional, latinoamericana y mundial. En Pasto cada 31 de diciembre hay desfile y quema de años viejos rememorando todos los sucesos malos que el año trajo, siendo este evento la antesala del carnaval, pues el 2 de enero se inicia con el oficio religioso en honor a la virgen de las Mercedes; luego los niños, niñas y adolescentes se toman la senda para presentar el Carnavalito, máxima expresión de arte popular infantil, semillero de artistas, cultores y gestores del futuro carnaval; y ya entrada la noche el festival del humor pastuso y música campesina pone a reír a todos los asistentes. Acto seguido, el 3 de enero el desfile de colectivos coreográficos y concierto de música andina latinoamericana deleitan al público con danzas, música, vestimentas coloridas y exuberantes expresiones de la cultura popular andina.

El 4 de enero, el desfile de la familia Castañeda rememora a los campesinos y colonos que iban y venían en búsqueda de mejores condiciones para sus familias. El 5 de enero, día de negros o día de la identidad, deleita con el exuberante legado africano recordando el día libre que tenían los esclavos para celebrar la vida. Con tambores, cununos y marimbas se baila y se canta en honor a la libertad y a los ancestros. $Y$ mucho antes del amanecer miles de gentes ataviadas con cobijas, ruanas, sombreros, comida y bebidas se arremolinan a lo largo de la senda del carnaval por donde pasa el desfile magno para no perder detalle alguno. La majestuosidad de las carrozas, las esculturas vivientes, los murales mágicos, las vestimentas coloridas, las coreografías vistosas, los músicos virtuosos y los danzantes expertos hacen posible que este desfile sea único en el mundo. Todos juegan, ríen, gritan y aplauden el apoteósico desfile del 6 de enero, día de los blancos y, para dar por 
terminado el carnaval, al día siguiente se remata con el festival del cuy y cultura campesina.

Es de resaltar que en la celebración del carnaval participan todos los sectores sociales de la ciudad, los corregimientos, las veredas y pueblos vecinos con sus tradiciones, costumbres y manifestaciones propias de su ser cultural. "Los espectadores no asisten al carnaval, sino que lo viven, ya que el carnaval está hecho para todo el pueblo. Durante el carnaval no hay otra vida que la del carnaval" (Bajtín, 1987, p.13). Dicho lo anterior, el carnaval es "un ritual para la interculturalidad, la intersubjetividad, la creación artística, el diseño escultórico, el reencuentro y la mixtura del pasado con el presente" (Mesa, 2016:210). Mantiene en su dinámica anual, el devenir de la historia de la humanidad, los gestores, los artistas y artesanos sintetizan, plasman y recrean el pensar, sentir y obrar de su pueblo, en la innovación de nuevos disfraces, coreografías, murgas y carrozas; ya lo dice la Unesco (2003:3): "los rituales y las fiestas suelen celebrarse en momentos y lugares especiales, y recuerdan a la comunidad aspectos de su visión del mundo y su historia".

En el contexto de la fiesta carnavalera, "la cultura adquiere formas diversas a través del tiempo y del espacio. Esta diversidad se manifiesta en la originalidad y la pluralidad de las identidades que caracterizan a los grupos y las sociedades que componen la humanidad" (Unesco, 2001:6). Las diferentes manifestaciones de un pueblo expresan la cultura como manifestación colectiva: "permite comprender cómo estos espacios festivos, lúdicos, simbólicos y la cultura inmaterial en sí, son fundamentales para la convivencia y el respeto por los otros" (Afanador, 2008:8).

\section{PENSAMIENTO ANDINO E INTERCULTURALIDAD.}

Las cosmovisiones, las prácticas ancestrales, la diversidad cultural y el pensamiento andino se articulan y conforman un marco epistémico para construir la paz. De las cosmovisiones y las prácticas ancestrales surgen reflexiones necesarias y pertinentes para el pensamiento andino, pues los Pastos condensan sus reflexiones en el Sol de los Pastos, iconografía representativa de su estructura social, económica y cultural. 
Las ocho puntas representan los estadios del espíritu humano, los ocho principios vitales: la familia, la salud, el placer, los amigos, la comunidad, los hijos, el saber y la riqueza.

De estos principios nacen los valores, los contenidos y las dimensiones que retoma el pensamiento andino: de la pachamama nace la unidad, la armonía, la complementariedad, la reciprocidad, la dimensión natural, material, laboral, productiva, intelectual y espiritual. La minga o manos prestadas evoca un ser para los demás, con capacidad para amar, servir y ayudar a sus semejantes y representa la dimensión colectiva, social, comunitaria, relacional y servicial. La religiosidad posibilita la relación sagrada con el universo, con la tierra, con las divinidades, con sus semejantes, consigo mismo y con la trascendencia. El humor pastuso despierta la risa, la ironía, la burla, la alegría, el esparcimiento y convoca a la felicidad. Y el carnaval nos enseña que la existencia humana se nutre de finuras filosóficas, estéticas, artísticas, festivas, celebrativas y creativas.

Por consiguiente, el pensamiento andino es una manera particular de reflexionar las realidades cotidianas, materiales y espirituales de los pueblos. Es una sabiduría sobre la vida en relación con el universo, el absoluto, la comunidad y la trascendencia. Es un saber que emana de las cosmovisiones y prácticas socioeconómicas, las cuales explican el origen y el devenir y dan sentido y significado a la existencia en este mundo; a su vez, son el sostén y el fundamento de la cultura, la cual es entendida como el pensar, sentir y obrar de un pueblo. El pensar posibilita la construcción del conocimiento; el sentir crea el arte expresado en belleza, armonía y bondad; y el obrar moldea las actitudes, los comportamientos y las conductas de los individuos y los pueblos.

Integrado a lo anterior, la diversidad cultural acrecienta su importancia, "la diversidad cultural es tan necesaria para el género humano como la diversidad biológica para los organismos vivos" (Unesco, 2001:2). En este sentido, constituye el patrimonio común de la humanidad y debe ser reconocida y consolidada en beneficio de las generaciones presentes y futuras. 
En la diversidad fluye la complejidad y conflictividad que gobiernan la vida; nacen mestizajes herederos de inconmensurable belleza y crea culturas para otros mundos posibles. Por esto, las culturas son el mayor tesoro de la humanidad, cada una es la arqueología del espíritu humano hacedor de conocimientos, artefactos, acciones éticas, estéticas y conductuales. Todas las culturas son importantes y necesarias en el devenir de las civilizaciones, sus cosmovisiones, prácticas, mestizajes, valores y particularidades son referentes para la comprensión del género humano.

Dentro de la diversidad se encuentra la multiculturalidad y la interculturalidad como escenarios interdisciplinarios, transdisciplinarios y metodológicos desde los cuales se gestionan y promueven los encuentros étnicos, lingüísticos, gastronómicos, festivos y culturales. La multiculturalidad refiere la existencia de distintos grupos culturales que, en la práctica social y política, permanecen separados, divididos y opuestos, mientras que la pluriculturalidad indica una convivencia de culturas en el mismo espacio territorial, dando origen al mestizaje, a la resistencia cultural y a la revitalización de las diferencias. En este punto, la interculturalidad agencia procesos de integración, comunicación e intercambio en búsqueda de altos niveles de diálogo, encuentro y asociación.

Entonces, la interculturalidad, puede ser entendida como un proceso permanente de relación, comunicación, integración y aprendizaje entre personas y grupos sociales; es, por tanto, un proceso de intercambios socioculturales, hibridaciones y mestizajes, transculturación, entre muchos otros. En este sentido Abello, et al (1999:209) afirman, que la noción de lo intercultural parte del hecho de que las culturas no se encuentran aisladas ni se producen por generación espontánea. Más bien, en su diario acontecer, tienden a abarcar un espacio que las conduce a entrar en relaciones con otras culturas. $Y$ esas relaciones que se establecen entre las culturas es lo que se denomina interculturalidad.

En este sentido el diálogo intercultural es fundamental para el aprendizaje de saberes, conocimientos, ciencia, tecnología, economía y espiritualidad, nos enseña que las experiencias sociales, las prácticas 
productivas, las técnicas agrícolas, los saberes pedagógicos, el sistema de valores, el ejercicio del poder, entre muchos otros enriquecen, fortalecen y consolidan la fraternidad entre los pueblos. También enseña que la interculturalidad debe estar fundamentada en el ejercicio de los derechos humanos, sociales y culturales y bajo los criterios de respeto, igualdad, equidad, disenso, concertación, integración y convivencia. En este sentido la Unesco (2001:3) recuerda que "inseparable de un contexto democrático, el pluralismo cultural es propicio para los intercambios culturales y el desarrollo de las capacidades creadoras que alimentan la vida pública".

De ahí que todo lo relacionado a políticas públicas respecto a diversidad cultural sea la salvaguardia de los derechos sociales y culturales de los pueblos. Al respecto Zambrano (2010:11) expresa que:

El Estado multicultural -que es un Estado Social de Derecho que reconoce y promueve la diversidad cultural como principio fundamental de su organización política, social e institucional - está ineludiblemente obligado por el deber estatal de proveer medidas legislativas y políticas públicas para salvaguardar los derechos consagrados para el ejercicio de la diferencia cultural de los ciudadanos, en igualdad de condiciones y sin menosprecio y menoscabo de ella.

De este modo no hay política cultural posible sin contar con las 'culturas políticas locales', Barbero (2005:55) confía que "las culturas tienen futuro mientras haya un mínimo de inteligencia por parte de los estados para asumir que lo que está en juego es a la vez, la diversidad local y la supervivencia mundial de los habitantes de este planeta"; por su parte, Zambrano (2006:30) declara que:

El camino del respeto de la diversidad no es el de unificar, sino es el de crear -primero que todo- una concepción de mundo, para identificarse progresiva e históricamente con las sucesivas dinámicas que emergen de la vitalidad de las culturas y para establecer una concordancia entre las palabras, los hechos y las acciones. 


\section{CONCEPTOS PARA CONSTRUIR LA PAZ REGIONAL}

El debate académico se suscita ante la inquietud de si las cosmovisiones, las prácticas ancestrales, la diversidad cultural y el pensamiento andino son referentes epistemológicos y pedagógicos para cimentar en ellos la construcción de la paz regional

\subsection{Pachamama y paz.}

Esta cosmovisión se fundamenta en el concepto espacio/tiempo y se recrea en la madre tierra. Puede entenderse desde una concepción cíclica que se autogobierna con el ayer, el hoy y el mañana en el devenir infinito. Los conceptos más importantes se agrupan en torno a unidad, reciprocidad, armonía, complementariedad, dualidad, transversalidad, tierra, chagra, naturaleza y universo. A continuación, se abordarán algunos de ellos.

El concepto de unidad gravita sobre la idea de que la pachamama es un cuerpo viviente compuesto por partes en mutua relación, el todo y las partes, nada está por fuera de la pachamama, todo nace y descansa en ella, es decir nada falta, ni nada sobra.

Se entiende la reciprocidad como una idea ancestral que involucra a todos los seres; dado que todos somos parte de la pachamama somos parientes unos de otros. A diferencia de las cosas y de los animales, el ser humano proviene del vientre de una madre, del útero materno, de la calidez humana y ésta es su primera y más grande experiencia. En este particular, "la mujer está ligada directamente a lo más complejo del universo, que es la vida" (Boff, 2013:20).

La reciprocidad comporta la armonía y el equilibrio, éste nace de la relación de las partes con el todo al mantener un punto de energía en la actividad gravitacional del universo. Sólo se alteraría con la acción destructiva del ser humano. Del equilibrio deviene la armonía, que es la correspondencia adecuada entre las acciones del hombre con la naturaleza, se refiere al accionar del hombre en la transformación de los contextos para su bienestar y felicidad. 
Cuando el egoísmo, la avaricia y la lujuria imperan sobre la razón y la emoción, la actividad del ser humano se desborda y se corrompe; por esto, el principio de reciprocidad recobra su significado y sentido porque hay que devolverle a la naturaleza lo que de ella hemos tomado, hay que restituirle lo que nos ha dado, hay que compensarle lo que hemos gastado, es decir, practicar la corresponsabilidad para garantizar la armonía y el equilibrio no sólo de la pachamama en sentido físiconatural, sino también de la comunidad en sentido relacional-social.

El concepto de armonía hace referencia a un estado en el cual el género humano interactúa con la madre naturaleza de manera responsable, sin alterar los ritmos, sin hacer saltos en los procesos y sin abusar de los recursos. La naturaleza es un ser vivo, determinado por sus propias leyes, que evoluciona de acuerdo con unos ciclos que la renuevan constantemente, independientemente de la actividad humana.

El concepto de complementariedad enseña que el género humano necesita de la madre tierra pues su vida depende absolutamente de la naturaleza. Por ello, el hombre está llamado a cuidar, proteger, renovar, recrear y conservar los recursos que son la vida misma, disponiendo todas sus capacidades al servicio de la madre tierra pues con su accionar la mejora o la destruye.

La pachamama es una entidad natural que provee de lo necesario a todos los seres que la habitan y en especial al género humano y en esa dinámica se inscribe 'para dar recibir', es decir, el dar para recibir y el recibir para dar, en una dinámica cotidiana, recibo lo que me da la naturaleza y de lo que recibo doy a otros.

La madre tierra provee los recursos, los medios, las semillas y los frutos para que el ser humano se beneficie y disfrute de ellos, para que aprenda a trabajar y alimentar a su familia. El trabajo es la actividad física, mental y emocional para transformar el medio natural para su bienestar, para su felicidad y para la dignidad humana.

Entonces la pachamama y el bien común son una sola realidad, son la base del bienestar social, pues el bien común es darle a cada uno lo 
que necesita para vivir con dignidad y ésta es la mejor y mayor expresión de justicia social y la base para la construcción de paz. En el concepto de bien común también se incluyen los servicios y los recursos, por esto el Estado tiene la obligación de ofrecerlos y garantizarlos a todas las personas. Al respecto el Papa Francisco (2015:49) afirma:

El bien común presupone el respeto a la persona humana en cuanto tal, con derechos básicos e inalienables ordenado a su desarrollo integral. También reclama el bienestar social y el desarrollo de los diversos grupos intermedios, aplicando el principio de la subsidiariedad. Entre ellos destaca especialmente la familia, como célula básica de la sociedad (...). El bien común requiere la paz social.

El bien común no es algo exclusivamente humano, sino de toda la comunidad cósmica. "Todo cuanto existe y vive merece existir, vivir y convivir. El bien común particular surge partiendo de la sintonía y sinergia con la dinámica del bien común planetario y universal” (Boff, 2013:25).

En este sentido, una idea fuerte para la construcción de la paz está relacionada con sostenibilidad y sustentabilidad de los recursos naturales. La ecología integral es inseparable de la noción de bien común, un principio que cumple un rol central y unificador en la ética social entendida como "el conjunto de condiciones de la vida social que hacen posible a las asociaciones y a cada uno de sus miembros el logro más pleno y más fácil de la propia perfección" (Papa Francisco, 2015:44).

\subsection{Minga y paz.}

La cosmovisión Minga o manos prestadas, se entiende como ayuda, solidaridad, servicio y tejido social. Esta concepción es esencial para la ayuda mutua, pues desde ella se fundamentan las relaciones sociales y familiares. Es un accionar ancestral a través del cual se mantiene una economía basada en el trabajo colaborativo. En tiempos de cosecha, en el enteje de una casa, en la construcción de una obra social, en la limpieza de caminos, por ejemplo, se necesitan manos y brazos, y a cambio de la ayuda se reciben alimentos o parte de la cosecha; de esa manera todos tienen lo básico para subsistir. 
Es necesario recalcar que la solidaridad es un valor importante y está directamente relacionado con las manos prestadas, es decir, que, gracias a una labor prestada, quien necesite recibe algo para el beneficio propio y el de su familia, no es asistencialismo, más bien, es un concepto atado al trabajo, en el sentido en que la madre tierra da lo necesario para vivir, entonces cada uno debe trabajar para conseguir el sustento. No ocurre lo mismo con el holgazán quien al no prestar sus manos para algo útil no merece recompensa alguna. La caridad no es dar por dar, también está relacionada a recibir para dar, es un ir y venir de una acción solidaria. Se ayuda a los huérfanos, a las madres abandonadas, a los ancianos y a los desvalidos.

En la dinámica de las comunidades se propician los matrimonios de miembros de distintas localidades para favorecer el intercambio de bienes, productos y servicios, de esa manera garantizar el bienestar de las familias, especialmente de los hijos. Esta dinámica en ascenso oxigena las relaciones parentales y posibilita interacciones sanas y fecundas. En pocas palabras, la minga simboliza en las manos prestadas la ayuda mutua, el servicio desinteresado, el trabajo colectivo, la solidaridad y refuerza el entramado social fuente de su estructura socio política. La minga también puede ayudar a construir la paz porque es solidaridad, servicio y bienestar social, construir la paz es construir la vida y desde la minga se construye la vida.

En consecuencia, de la cosmovisión pachamama y minga se desprenden acciones económicas que fundamentan el tejido social y el buen vivir. La madre tierra ofrece todos los recursos y materiales; el ser humano con su inteligencia y trabajo consigue los frutos para vivir; mediante la práctica de las manos prestadas se consolidan las relaciones sociales necesarias para la vida comunitaria y familiar. Entonces, el buen vivir no está relacionado directamente con el tener más, sino con la satisfacción del disfrute de lo que la madre tierra da en comunión con los demás. El sentido de lo comunitario es necesario y representa identidad, con lo cual se sustenta la idea de pertenencia y se sostiene el significado de alteridad.

Las comunidades, en este sentido, practican la reciprocidad en términos de alteridad, porque en las actividades agrícolas, económicas 
y comerciales tienen en cuenta al otro en su necesidad, por ello son importantes las acciones colectivas, como "la payacua que consiste en ir a donde están cosechando, llevándole al dueño de la cosecha algo que necesite en su labor inmediata, y él corresponde con lo de su cosecha" (Mamián, 2004:63)

La ración o escogidas es lo que el mingante dueño de brazo o trabajo escoge de la cosecha y lleva a su hogar, la medida es la milla o el millado, es decir, lo que alcanza en la punta doblada del pañolón, en el caso de la mujer, o del poncho (ruana) en el caso del hombre. El agrado es el regalo que se lleva a un pariente o amigo que visita porque hay que compartir de lo que Dios da.

En la cosecha de papa, oca, maíz o frijol, a veces aparecen frutos de colores contrastados, entonces se los entrevera con los normales y se los lleva a un amigo, compadre o pariente, quien lo recibe queda misiado de misiar, es decir que al año siguiente tiene que donarle productos de su cosecha.

Las recogidas se refieren al acto establecido como posibilidad y derecho, que realizan las mujeres, los ancianos y los niños, de acercarse donde estén cosechando y, detrás, ir recogiendo lo que sin proponérselo los cosechadores van dejando. En la cosecha de trigo y cebada a quienes tienen la costumbre de recoger las espigas y atarlas formando chullas se les denomina chuliadores.

En pocas palabras, la minga colectiva se podría resumir en lo siguiente, le presto mis manos, usted no me paga, pero cuando yo tenga la necesidad usted me presta las suyas.

\subsection{Religiosidad y paz.}

En la relación del ser humano con la naturaleza se suscitan imaginarios colectivos acerca de lo religioso, lo sagrado, lo divino, lo espiritual que da origen a las manifestaciones y prácticas cultuales, rituales y ceremoniales, este es el origen de la religiosidad de casi todos los pueblos. 
Históricamente el encuentro entre culturas se dio a través de un proceso de aculturación e imposición de una sobre otra, originando el coloniaje y mestizaje. Durante este periodo se mezclaron aspectos de las diferentes religiones, dando origen a la religiosidad popular desde la cual el pueblo creyente expresa su fe. Los misioneros españoles para adoctrinar a los pueblos retomaron elementos de la cultura nativa y los juntaron con elementos de la doctrina cristiana; en el transcurrir del tiempo, se mezclaron de tal manera que hoy es imposible hacer separaciones porque es una mezcla compacta, sólida, fecunda. Así, el origen de la religiosidad popular es un fenómeno cultural conocido como sincretismo religioso que propicia la mezcla de aspectos sagrados y paganos para expresar la fe y las creencias.

En perspectiva cristiana, la doctrina se sostiene en tres aspectos: amor, perdón y caridad. Lo que significa que el cristianismo es un estilo de vida basado en el amor como la primera condición para vivir el mensaje de Cristo; el perdón como la condición para reparar las acciones provenientes del egoísmo, el odio y la venganza; y la caridad como la actitud de servicio y entrega a la humanidad, sin la cual no es posible el amor. No obstante, en el proceso del sincretismo religioso, no todo ha sido claro y transparente porque se ha privilegiado más la norma, el dogma, el castigo que el amor, el perdón y la caridad.

\subsection{Humor y paz.}

En el suroccidente colombiano, especialmente en los andes nariñenses, el cuento pastuso reúne historia, modernización, identidad cultural y regionalismo, por esto posibilita la risa, la alegría y el esparcimiento. El humor genera la idea optimista acerca de que la vida hay que vivirla con entusiasmo, aprendiendo a disfrutar y gozar cada momento, cada situación, entendiendo las adversidades como oportunidades y no como fracasos. También, permite entender que la vida es una sola, aquí y ahora, por tanto, es menester saberla vivir en la cotidianidad de la existencia.

La concepción humorista enseña que la alegría es un ingrediente fundamental de la existencia humana, que es necesario expresar los sentimientos placenteros, que es bueno sonreír, mantener un buen 
estado de ánimo, porque ello dispone a las personas al diálogo, a la escucha, a la tolerancia, a la solidaridad y a la paz. Las personas alegres contagian a otras, las personas optimistas abren puertas, las personas sonrientes animan a los tristes, es decir, el buen humor serena los ánimos, predispone el espíritu y activa la creatividad.

En sentido particular, el humor es un dispositivo terapéutico, porque provoca la risa colectiva, contagia a los espectadores, predispone las actitudes tolerantes, solidarias, comprensivas y es necesario e importante en la convivencia, en las relaciones interpersonales, en la transformación de los conflictos y en la construcción de paz. Y es que el humor no tiene edad, ni color de piel, ni credo religioso, ni ideología; el humor es arte, y el arte es el escenario para la felicidad porque enaltece la estética en sus más expresivos ropajes de belleza, armonía y bondad. Por esto, un pueblo que aprende a reír, a celebrar y gozar es un pueblo alegre, feliz y próspero.

\subsection{Carnaval y paz.}

El carnaval es un ritual festivo, una expresión de la cultura popular, una oportunidad para el arte, la estética y la ética. Mesa (2016:3) afirma que es "un maravilloso escenario para el encuentro intercultural". Por su parte Bajtín (1987:8) afirma que "es la segunda vida del pueblo, basada en el principio de la risa. Es su vida festiva", Así mismo, la Unesco (2003:2) dice que "Ios rituales y las fiestas suelen celebrarse en momentos y lugares especiales, y recuerdan a la comunidad aspectos de su visión del mundo y su historia". Es una fiesta colectiva en donde unos y otros se reúnen para celebrar la vida, sin distingos sociales, ni abolengos, ni cargos públicos, es la fiesta de todos. Se vive a través del juego, es jugando que se celebra el carnaval, echando talco, untando cosméticos, persiguiendo al otro, bailando aquí y allá; en el juego colectivo está la esencia, por esto es una oportunidad para la tolerancia, el respeto, la igualdad y la construcción de ambientes sanos, positivos y pacíficos.

Entonces es un ritual festivo que se repite cada año de manera cíclica, rememora el pasado, confiere significado al presente y vislumbra el futuro. Así, se constituye en un acto simbólico y de memoria colectiva, 
se enriquece de los conocimientos, experiencias y visiones de las nuevas generaciones. En este sentido, el carnaval es el escenario para el diálogo intercultural porque participan todos los rostros étnicos y todas las expresiones culturales de la región, es decir, la multiculturalidad se regocija en el abrazo fraterno y le confiere trascendencia a la pluralidad, a la conflictividad y a la complejidad, aspectos constitutivos de la interculturalidad.

En definitiva, la celebración carnavalesca es una convocatoria a la paz, a la fiesta pacífica y al goce colectivo, por esto el carnaval es un territorio de paz porque aquí llega Raimundo y todo el mundo, evoca la hora de recreo en la escuela, el juego, la merienda, la risa, la alegría y el júbilo. Aprender a jugar jugando es maravilloso porque cada uno aporta al juego, pero cuando no se entiende bien y no se cumplen las normas del juego, el mismo grupo llama la atención. Estos momentos de tolerancia son fundamentales para continuar el juego. En este sentido, la tolerancia es un valor muy cercano a la amistad, al compañerismo, al paisanaje; estos espacios de tolerancia son lecciones de paz y eso hay que aprenderlo.

Por consiguiente, el carnaval es el juego de la vida, en su celebración se viven todas las experiencias posibles, o como dice la canción: La vida es un carnaval (1998) de Celia Cruz: "Hay, no hay que llorar, que la vida es un carnaval, que es más bello vivir cantando. Ooo ay, no hay que llorar, que la vida es un carnaval, y las penas se van cantando".

\section{CONCLUSIONES}

Las cosmovisiones y prácticas ancestrales de los Pastos son un conjunto de principios, valores, conceptos y acciones que enriquecen y fortalecen la organización social, económica, política, cultural y educativa de las comunidades de la región andina nariñense. Son marcos constitutivos de la identidad cultural y recrean las concepciones filosóficas, estéticas, éticas y conductuales de los individuos y de los pueblos.

Las prácticas ancestrales son modos de vida, acciones y actividades cotidianas, solidarias y participativas en la dinámica socioeconómica 
pues promueven la sostenibilidad medio ambiental, la seguridad y la soberanía alimentaria; fortalecen las relaciones sociales, la economía doméstica, el respeto a la diferencia y el buen vivir; y recuerdan que las festividades religiosas, cívicas y políticas son ciclos vitales de la existencia.

En el marco del respeto y garantía de los derechos humanos, sociales, económicos y culturales, el diálogo intercultural es fundamental para el intercambio de saberes, conocimientos, tecnología, literatura, arte, espiritualidad y construcción de paz regional.

\section{REFERENCIAS}

(1) Abelllo, I., De Zubiría, S. y Sánchez, S. (1999). Cultura: teorías y gestión. Ediciones Unariño. Pasto.

(2) Afanador, C. (2011). Organización espacial de los Pastos coloniales. En: Academia Nariñense de Historia. Pasto.

(3) Afanador, C., Tovar, J. y Reyes, Á. (2008). Dossier del Carnaval de Negros y Blancos. Ediciones Corpocarnaval. Pasto.

(4) Bajtín, M. (1987). La cultura popular en la edad Media y el Renacimiento. El contexto de François Rebeláis. Editorial Alianza. Madrid.

(5) Barbero, J. M. (2005). "Interculturalidad, desafíos a la Nación y políticas públicas". En: Cuadernos de Sociología, №39, pp. 53-59. Bogotá.

(6) Boff, L. (2013). La sostenibilidad: qué es y qué no es. Editorial Sal Terrae. España.

(7) Geertz, C. (2003). La Interpretación de las culturas. Editorial Gedisa S.A. España.

(8) Huanacuni, F. (2010). Buen vivir/Vivir Bien. Filosofía, políticas, estrategias y experiencia regionales andinas. Editorial CAOI. Lima. 
(9) Mamián, D. (2004). Los Pastos en la danza del espacio, el tiempo y el poder. Ediciones Unariño. Pasto.

(10) Mesa, E. (2016). El carnaval, escenario para el encuentro Intercultural. EdA Special Issue, pp.320-325. Florencia, Italia.

(11) Montenegro, A. (2002). Una historia en contravía: Pasto y Colombia. Editorial Malpensante. Bogotá.

(12) Muñoz, F. y Molina, B. (1998). Cosmovisiones de Paz en el mediterráneo. Editorial Universidad de Granada. España.

(13) Papa Francisco (2015). Carta Encíclica Laudato Sí. Sobre el Cuidado de la Casa Común. Disponible http://w2.vatican.va/content/francesco/es/encyclicals/ documents/papa-francesco_20150524_enciclica-laudato-si.htm (Recuperado en: abril 29 de 2018)

(14) Sanz, R. (2006). Diccionario de la Lengua Pastusa. Ediciones Graficolor. Pasto.

(15) UNESCO (2001). Declaración Universal sobre Diversidad Cultural. Disponible en: http://unesdoc.unesco.org/images/0012/001271/127162s.pdf (Recuperado en abril, 2-18)

(16) UNESCO (2003). Convención para la Salvaguardia del Patrimonio Cultural Inmaterial. Disponible en: http://unesdoc.unesco.org/ images/0013/001325/132540s.pdf (Recuperado en mayo, 16 de 2018)

(17) Zambrano, C. V. (2006). Ejes políticos de la diversidad cultural. Universidad Nacional de Colombia. Siglo de Hombres Editores. Bogotá.

(18) Zambrano, C. V. (2010). "Territorio, diversidad cultural y trabajo social". En: Revista Trabajo Social, № 12 pp. 9-24. Bogotá.

(19) Zúñiga, E. (2002). Nariño, Cultura e Ideología. Graficolor. Pasto. 